\title{
Expanding Earth and declining gravity: a chapter in the recent history of geophysics
}

\author{
H. Kragh \\ Niels Bohr Archive, Niels Bohr Institute, Blegdamsvej 17, 2100 Copenhagen, Denmark \\ Correspondence to: H. Kragh (helge.kragh@nbi.ku.dk)
}

Received: 4 February 2015 - Accepted: 16 April 2015 - Published: 5 May 2015

\begin{abstract}
Although speculative ideas of an expanding Earth can be found before World War II, it was only in the 1950s and 1960s that the theory attracted serious attention among a minority of earth scientists. While some of the proponents of the expanding Earth adopted an empiricist attitude by disregarding the physical cause of the assumed expansion, others argued that the cause, either fully or in part, was of cosmological origin. They referred to the possibility that the gravitational constant was slowly decreasing in time, as first suggested by P. Dirac in 1937. As a result of a stronger gravitation in the past, the ancient Earth would have been smaller than today. The gravitational argument for an expanding Earth was proposed by P. Jordan and L. Egyed in the 1950s and during the next 2 decades it was discussed by several physicists, astronomers and earth scientists. Among those who for a period felt attracted by "gravitational expansionism" were A. Holmes, J. Tuzo Wilson and F. Hoyle. The paper examines the idea of a varying gravitational constant and its impact on geophysics in the period from about 1955 to the mid-1970s.
\end{abstract}

\section{Introduction}

Today it is often forgotten that the epic debate about Earth in the years from about 1955 to 1970 involved three and not merely two rival theories. In addition to continental drift and the traditional picture of an essentially static Earth, a minority of scientists discussed and sometimes advocated the idea of an expanding Earth. Expansionism was evidently on the side of mobilism and against fixism, but at the same time it was opposed to continental drift in the sense of Alfred Wegener. Although many modern earth scientists may be unaware of the expansion theory of the past, its role in the plate tectonics revolution is documented in the historical literature (Menard, 1986; Le Grand, 1988; Oldroyd, 1996; Nunan, 1998). On the other hand, there are also participants' histories of the revolution in which the expanding Earth alternative is not even mentioned (Oreskes, 2001). The most scholarly work on the subject is contained in Henry Frankel's four-volume work on the history of plate tectonics (Frankel, 2012a). However, with the exception of a recent paper on modern attempts to keep expansionism alive (Sudiro, 2014), there are no historical studies that focus on the expanding Earth research programme in its own right and not merely as an appendix to the development of plate tectonics (but see Nunan, 1988 for a philosophical perspective).

According to continental drift there had always been continents and oceans, but their patterns of distribution have changed as the continents separated on the surface of the constant-sized Earth. By contrast, there were no oceans in the expansionists' picture of the original Earth, which was completely covered by a sialic crust; only with the expansion of Earth and the resulting cracks in the crust did the oceans appear. Expansionists disagreed about the finer details of the history of Earth, but all agreed that the continents had separated as a result of an increased size of the globe. There was little unity among the expansionists, some of whom focused on the mechanism driving the supposed expansion while others were unconcerned with its cause. While most were in favour of a slow increase of Earth's radius $\left(\sim 0.5 \mathrm{~mm} \mathrm{yr}^{-1}\right)$, a minority argued for a greater expansion rate $\left(\sim 5 \mathrm{~mm} \mathrm{yr}^{-1}\right)$. Again, whereas some expansionists considered the hypothesis an alternative to continental drift, there were also those who considered the two hypotheses to be compatible and complementary.

Among the suggested mechanisms for the expansion, should it be real, was the cosmological hypothesis that the 
gravitational constant $G$ decreases with the age of the universe, what I refer to as the $G(t)$ hypothesis. This essay is primarily a study of the surprising connection between two nonmainstream hypotheses, one belonging to cosmology and the other to geophysics. In the period from about 1955 to 1975 , the gravitationally caused expansion of Earth was widely discussed although only supported by a handful of scientists. There was in some quarters a feeling that new physical and cosmological ideas might well play a role in the still unfinished revolution in the earth sciences. As Holmes (1965, p. 35) expressed it, "New ideas of atomic structure at one end of the scale of dimensions and of the expanding universe at the other, necessarily demand new ideas about the Earth herself." The case is not well known in either the history of cosmology or in the history of geophysics, but it is of considerable interest not least because it illustrates an unusual example of interdisciplinary research. The two hypotheses were independent in the sense that the conjecture of varying gravity did not rely crucially on Earth expansion, nor did the latter hypothesis rely crucially on varying gravity. As it happened, both hypotheses turned out to be wrong. Although this is important from a scientific point of view, it is largely irrelevant from the point of view of the history of science.

\section{Dirac's gravitation hypothesis}

The idea that the gravitational constant varies in time (and thus is not a true constant) was originally suggested quite independently of geophysics. The context was the universe, not Earth. Paul Dirac, Nobel Prize laureate and famous quantum physicist, was concerned with the interrelationship of the very large dimensionless combinations of constants of nature (Dirac, 1937; Kragh, 1990, pp. 223-235). One such number is

$$
\frac{e^{2}}{G m M} \cong 10^{39}
$$

where $e$ is the elementary charge and $m$ and $M$ the mass of the electron and the proton, respectively. Another pure number of the order of $10^{39}$ is the age of the universe expressed in "atomic time units" $e^{2} / m c^{3}$, where $c$ is the speed of light in a vacuum. On the basis of this order-of-magnitude agreement Dirac suggested that the gravitational constant varies inversely with the age of the universe:

$$
G \sim \frac{1}{t} \text { or } \frac{1}{G} \frac{\mathrm{d} G}{\mathrm{~d} t} \sim-\frac{1}{t} .
$$

Thus, at the time of the formation of Earth some 4.5 billion years ago gravity was assumed to be much stronger than today. Following up on the idea Dirac (1938) developed it into a cosmological model of the expanding universe. According to this model $G$ decreased as

$$
\frac{1}{G} \frac{\mathrm{d} G}{\mathrm{~d} t}=-3 H_{0}=-\frac{3}{T_{0}},
$$

$H_{0}$ denotes the Hubble constant, which at the time was believed to be $H_{0} \cong 500 \mathrm{~km} \mathrm{~s}^{-1} \mathrm{Mpc}^{-1}$, and $T_{0}=1 / H_{0} \cong$ $1.8 \times 10^{9}$ years is the Hubble time. The unit Mpc stands for megaparsec $\left(10^{6} \mathrm{pc}\right), 1 \mathrm{pc}=3.1 \times 10^{16} \mathrm{~m}$. With this value for $H_{0}$ it follows that the relative change of $G$ is of the order of $10^{-10}$ per year. Dirac's cosmological model was not received favourably by either physicists or astronomers. The reason was not only the unorthodox $G(t)$ hypothesis, which implied that Dirac's model contradicted Einstein's fundamental theory of general relativity (according to which $G$ is constant) but also the an embarrassingly small age of the universe that followed from the model. According to Dirac's theory the age was given by $T_{0} / 3$ and thus markedly less than the age of Earth as determined by radiometric methods.

While Dirac did not refer to terrestrial consequences of his gravitation hypothesis, this is what the nuclear physicist Edward Teller did say in a much-discussed paper of 1948 in which he argued that the hypothesis leads to apparently insuperable problems of a palaeoclimatic nature (Teller, 1948). The value of $G$ determines the Sun's luminosity and therefore also Earth's surface temperature. According to Teller's calculations, 200-300 million years ago the temperature of Earth's surface would be close to the boiling point of water. Since this contradicted palaeontological evidence of a rich marine life at the time, he concluded that Dirac's $G(t)$ hypothesis was refuted. As George Gamow wrote in a letter to Dirac dated 27 April 1967, "the oceans must have been frozen during the Cambrian and still earlier eras" (Kragh, 1991, p. 116).

Neither Teller nor Dirac considered the effect of $G(t)$ on the size of Earth in the past. Teller's article was cited by several physicists and astronomers in the years 1948-1968, but it took until 1962 before it appeared in the geophysical literature. It was then in a paper written by two physicists (Peebles and Dicke, 1962).

\section{Jordan and the expanding Earth}

Like Dirac, the German theoretical physicist Pascual Jordan was one of the founders of quantum mechanics and known in particular for his seminal contributions to quantum field theory (Fig. 1). Alone among the physicists of prominence, Jordan was instantly captivated by Dirac's idea of a varying $G$, which in 1952 he described as "one of the great insights of our time" (Jordan, 1952, p. 137). In a series of papers starting in 1937 and culminating 10 years later with the monograph Der Herkunft die Sterne (The Origin of the Stars), Jordan developed his own system of cosmology and astrophysics based on Dirac's idea. In the late 1940s he presented a generalised version of Einstein's theory of general relativity which accommodated the non-Einsteinian feature of a varying $G$. Apart from a few references to the age of Earth, Jordan did not relate Dirac's hypothesis to issues of geology or geophysics. But he did so a few years later, when he began 


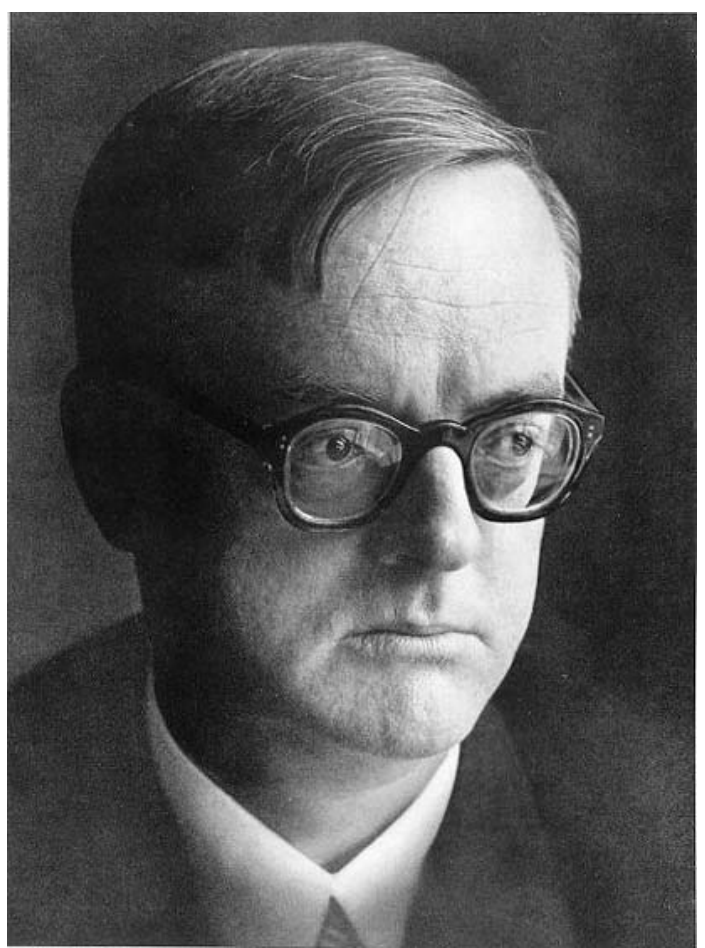

Figure 1. Pascual Jordan (1902-1980); http://www.gecoas.com/ religion/SUBPAG/HISTORIA/cientificos/imag/jordan.jpg.

focusing on Earth as a testing ground for cosmological theories in general and for the $G(t)$ hypothesis in particular.

The theme first appeared in a book of 1952 entitled Schwerkraft und Weltall (Gravitation and Cosmos). In a letter to his physics colleague Wolfgang Pauli, to whom he had sent a copy of the book, Jordan told that he was now engaged in finding evidence from the earth sciences that "the gravitational constant was larger a few billion years ago than it is now." One such piece of evidence was that "the composition of the surface of Earth seems to indicate that the surface has increased by a factor 2 or 3 since the Earth was formed" (Pauli, 1996, p. 800).

Thus, by 1952 Jordan had arrived at the conclusion that Earth was probably expanding as a result of the decreasing gravitational force. This result he ascribed to an American friend of his, a businessman and amateur geologist by the name Joel E. Fisher. In the revised edition of Schwerkraft und Weltall that appeared in 1955, Jordan dealt in more detail with the geophysical consequences of $G(t)$, including the expansion of Earth. These consequences, he wrote in the preface, ought to "attract attention among astronomers, geophysicists, geologists and palaeoclimatologists." Relating to a possible alternative to Wegener's theory of continental drift, Jordan continued: "The globe has increased in size since the surface of the Earth solidified.... The expansion of the Earth followed as the result of the decrease of $\kappa\left[=8 \pi G / c^{2}\right]$. This is the answer given by Joel Fisher" (Jor- dan, 1955, p. vi). As Jordan (referring to himself in third person) recalled at a later occasion, his interest in geophysics started

... when his late friend Fisher in New York made the remark that Dirac's decrease of $G$, if it existed, must have caused a marked expansion of the Earth in the course of its history. The author believed that here could be seen a possible answer to one of the great problems of Earth research: why is there a division of the surface of the Earth into two different parts, continental areas and deep sea? (Jordan, 1969, p. 55)

While Wegener (1966, pp. 35-40) thought that this socalled hypsographic problem could be explained by continental drift, to Jordan it was evidence of an expanding Earth and ultimately of a decreasing $G$ (see also Joksch, 1955). His basic argument was that, since Earth consisted of a compressed core and a non-compressed crust, the diminishing gravity would cause the core to expand as a result of the reduced weight of the overlying layer of rock. The crust itself would consequently break up and the cracks would be filled by upward movement of the underlying molten basalt. As he expressed it in a paper of 1962, "A process of expansion caused the continental layer to split into parts; the newly formed rifts were filled out to the equilibrium altitude by the more dense but also more mobile sima material of the deeper layer" (Jordan, 1962b, p. 286). The total area of granitic continents today would thus be equal to the surface of a smaller ancient Earth.

From 1952 until the mid-1970s Jordan published widely on a variety of subjects related to his favoured theory of a gravity-driven expanding Earth. Among the issues that he thought could be explained in terms of the theory were volcanism, the formation of mountains, Earth's climate in the past (including the ice ages) and the history of the Moon. In 1966 he summarised his work in the monograph Die Expansion der Erde which 5 years later appeared in an English translation as The Expanding Earth. While admitting that the evidence in support of the expanding Earth was indirect and subject to some doubt, Jordan was convinced that the total amount of evidence proved the correctness of the theory. Even more importantly, "our present knowledge of the Earth ... makes the correctness of Dirac's hypothesis an established fact" (Jordan, 1962a, p. 600).

Although Jordan's campaign for the $G(t)$ version the expanding Earth was not without effect, basically it was unsuccessful. Many of the British and American earth scientists who dominated the scene of geophysics in the 1950s and 1960s were unaware of Jordan's work which was mostly published in German and not in the mainstream geophysical literature. To a large extent his theories were overshadowed by those of the Princeton physicist Robert Dicke, who published in English and in the form of papers in widely circulated journals (Kragh, 2015). Dicke investigated the $G(t)$ 
hypothesis and believed, like Jordan, that it might result in an expansion of Earth. But according to Dicke, $G$ decreased at such a small rate that the corresponding increase in radius would be no more than $0.05 \mathrm{~mm}$ per year. Moreover, while Jordan saw the expanding Earth as an alternative to continental drift, Dicke was open to the possibility of drifting continents caused by convection currents in Earth's mantle.

When Jordan's The Expanding Earth appeared in 1971, continental drift in the form of plate tectonics had become the preferred theory of the history of Earth. The theory of the expanding Earth was no longer considered a serious alternative by the majority of earth scientists. As noted by Le Grand (1988, p. 227), "When in 1971 his monograph on Earth expansion was translated into English, it not only was out-of-date in terms of its geology but also had been overtaken by the emergence of newer versions of Drift including plate tectonics." As Jordan's extensive work on the expanding Earth and a varying $G$ received only limited attention in the 1960s, it has left almost no marks at all in the few historical accounts dealing with the role of the expanding Earth during the plate tectonics revolution; for example, it is not even mentioned in the histories of Frankel (2012a) and Nunan $(1988,1998)$.

\section{Egyed's slow expansion}

While Jordan was undoubtedly a pioneer of the modern version of the expanding Earth, it was only with the work of the Hungarian geophysicist László Egyed, director of the Geophysical Institute in Budapest, that "the expansion hypothesis entered the normal literature of science" (Menard, 1986, p. 144; Fig. 2). Based on palaeogeographical and other evidence Egyed, concluded in the mid-1950s that the radius of Earth had been expanding for the past 500 million years by the slow rate of $0.4-0.6 \mathrm{~mm}$ per year (Egyed, 1956a, b; Frankel, 2012a, pp. 279-282). He assumed the rate to have been constant throughout the period. Among the evidence which inspired Egyed to his conclusion were estimates of the change of water-covered continents through the history of Earth. According to Henri and Geneviève Termier at the University of Paris, the area had decreased. The Termiers did not intervene in the controversy over the expanding Earth except that they concluded that "global palaeogeography does not display any argument against Earth expansion" (Termier and Termier, 1969, p. 101; my emphasis).

To account for the expansion, Egyed adopted a modified version of a theory of the composition of the inner Earth first proposed by the British geophysicist William H. Ramsey at Manchester University in the late 1940s. Rather than explaining the difference between core and mantle chemically, Ramsay explained the core by a phase transition of silicate compounds such as olivine into a metallic state due to extremely high pressure (Ramsay, 1949; Brush, 1996, pp. 209-213). Egyed suggested that the inner core was a remnant of the

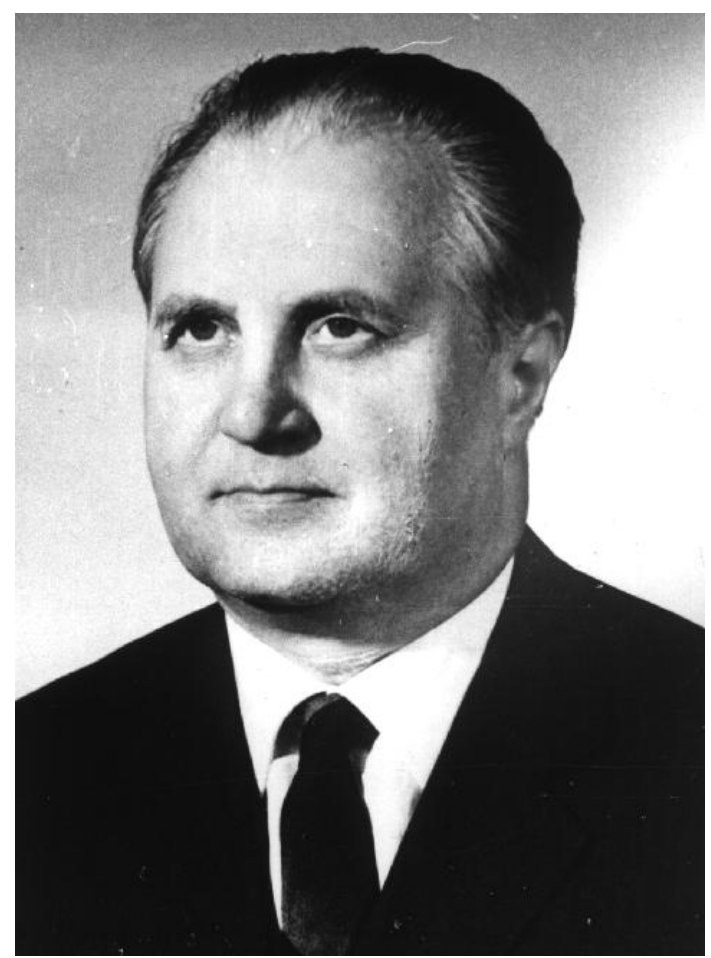

Figure 2. László Egyed (1914-1970); http://geophysics.elte.hu/ inmemoriam/egyed.jpg.

original solar material with a minimum density of $17 \mathrm{~g} \mathrm{~cm}^{-3}$ and that the density of the outer core was $9-12 \mathrm{~g} \mathrm{~cm}^{-3}$. He further argued that the matter of the inner core slowly and irreversibly transformed into a stable low-density phase, implying a decrease in the mean density of Earth. Assuming the mass of Earth to be constant he was then lead to "the surprising conclusion that the volume of the Earth is steadily increasing" (Egyed, 1957, p. 106). As a result of the expansion a large amount of tectonic energy would be released. Egyed's theory was ambitious and total in scope (Egyed, 1957, p. 101):

The expansion of Earth is able to account for the formation of the crust and oceanic basins, the energies of the tectonic forces and earthquakes, the origin of deep-focus earthquakes, the periodicity of geological phenomena, the continental drift and mountain building, and is supported also by palaeogeographical data.

By the late 1950s Egyed thought he had found an alternative or supplementary explanation for the expansion in Dirac's cosmological hypothesis of a decreasing gravitational constant, or what he called the "Dirac-Gilbert equation." This was a reference to the British mathematical physicist C. Gilbert according to whom Dirac's variation $G \sim 1 / t$ was consistent and could even be derived from the principles of general relativity (Gilbert, 1956). Although Egyed and a few other scientists accepted Gilbert's claim, the large majority of specialists in general relativity did not. They 
maintained - and still maintain - that a varying $G$ is irreconcilable with Einstein's theory of gravitation.

Nevertheless, on the basis of Dirac's gravitation hypothesis Egyed revised his picture of the structure of Earth and its evolution over time (Egyed, 1960a). Originally trained in physics and mathematics, Egyed was apparently aware of Dirac's hypothesis in the late 1930s. However, as he wrote in a letter to Arthur Holmes dated 31 July 1959, "at that time, I shared the doubts of most physicists concerning this hypothesis" (Frankel, 2012a, p. 285). It was only after Gilbert's argument that the $G(t)$ hypothesis agreed with general relativity that he accepted the hypothesis and made it the basis of his view of an expanding Earth. Egyed was in contact with Jordan, who was happy to have found a brother in arms. The noted Hungarian geophysicist, Jordan (1962b, p. 287) wrote, "now prefers to believe that Dirac's hypothesis is correct and gives the theoretical explanation of this expansion, which Egyed believes to be an empirically proven fact."

In a paper dated 1958 Egyed and his Hungarian collaborator Lajos Stegena derived from the Dirac-Gilbert hypothesis and the assumption of Earth's core mentioned above that the annual increase in the radius of Earth was at least $0.3 \mathrm{~mm}$, hence "almost identical with the lower limit of radius increase as determined from observations" (Egyed and Stegena, 1958, p. 266); 2 years later, in a popular review of geophysics, Egyed repeated his empirical arguments in favour of the expanding Earth, adding that the theory provided a simpler and more unified picture of Earth's surface than other theories. He suggested that without Gilbert's alleged proof there would have been no reason to take Dirac's hypothesis seriously (Egyed, 1965, p. 100; translation of Hungarian original of 1960):

On the basis of rather complicated and unclear considerations of a mostly philosophical nature, in 1939 [sic] Dirac concluded that the gravitational attraction had continually decreased during the lifetime of Earth, that is, the gravitational coefficient becomes smaller. Physicists used to exact scientific reasoning received the result with considerable distrust, and that despite that it came from a physicist as famous as Dirac.

At the time Egyed was aware of S. Warren Carey's independent work on the expansion of Earth, of which Arthur Holmes had informed him (Carey, 1958; Frankel, 2012a, p. 289). He also knew about Jordan's Schwerkraft und Weltall. According to Egyed's slow expansion, the radius of Earth had increased with approximately $500 \mathrm{~km}$ during the last billion years (Table 1).

Contrary to some other expansionists, Egyed did not consider the expansion hypothesis a proper alternative to the idea of drifting continents. On the contrary, it provided a partial explanation of drift or spread that avoided the controversial notion of continents moving with respect to the mantle: "In case the Earth is expanding, continental drift is nothing more than the formation of new ocean basins along the gaping rifts which come to exist between continents" (Egyed, 1960b).
Table 1. The gravitational constant $G$, Earth's surface gravity $g$, and Earth's palaeoradius $R$ at various times $T$ before the present. The figures assume Egyed's slow expansion of $\mathrm{d} R / \mathrm{d} t=0.5 \mathrm{~mm}$ per year and Dirac's $\mathrm{d} G / G \mathrm{~d} t=10^{-10}$ per year (and a constant mass of Earth). Adapted from Stewart (1970).

\begin{tabular}{rlrrr}
\hline$T$ & Epoch & $\begin{array}{r}G \\
\left(10^{-11} \mathrm{~N} \mathrm{~m}^{2} \mathrm{~kg}^{-2}\right)\end{array}$ & $\begin{array}{r}g \\
\left(\mathrm{~m} \mathrm{~s}^{-2}\right)\end{array}$ & $\begin{array}{r}R \\
\left(10^{4} \mathrm{~m}\right)\end{array}$ \\
\hline 2000 & Orosirian & 8.00 & 16.6 & 537 \\
1000 & Tonian & 7.34 & 12.7 & 587 \\
500 & Furongian & 7.00 & 11.2 & 612 \\
250 & Early Triassic & 6.83 & 10.4 & 625 \\
0 & Present & 6.67 & 9.8 & 637 \\
\hline
\end{tabular}

At a conference in Newcastle in 1967, Egyed (1969a) once again defended the slow expansion hypothesis, now arguing for an average rate of Earth's radius of $0.65 \pm 0.15 \mathrm{~mm}$ per year. He considered Dirac's $G(t)$ to be part of the explanation, but not the only explanation of why Earth expands. In addition to $G(t)$ he thought that natural radioactivity and phase changes at high pressure played a role. Without these mechanisms expansion would be unable to explain continental disruption.

Until his death in 1970, Egyed continued to support the expanding Earth and Dirac's $G(t)$ hypothesis, such as is evident from a textbook in geophysics published in 1969. "From Ramsey's model of the Earth and Dirac's cosmology," he wrote, "follow directly the expansion of the Earth" (Egyed, 1969b, p. 279). Egyed thought to have found additional evidence in palaeomagnetism and also in a suggestion made by John Wells, a geology professor at Cornell University and a specialist in fossil corals. Wells' idea was that the number of days per year in the geological past - and hence the speed of rotation of Earth round its axis - could be inferred from the variation in the deposition of calcium carbonate in fossil corals (Wells, 1963). By comparing the tiny daily rings with the broader annual bands he found that in the Devonian the year consisted of 400 days, or that in the course of 370 million years Earth's rotation had slowed down from 22 to $24 \mathrm{~h}$.

Assuming that the faster rotation of Earth in the past could be ascribed to a smaller radius, Egyed (1969b, p. 278) derived from Wells' preliminary coral data that the annual increase of Earth's radius in the upper Carboniferous was $\Delta R=0.58 \mathrm{~mm}$ and $\Delta R=0.74 \mathrm{~mm}$ in the Middle Devonian. This agreed nicely with his favoured slow expansion rate, but unfortunately the uncertainties in the method turned out to be too great to warrant Egyed's conclusion. The work of Wells and others on the growth rings of corals as a method of determining Earth's rotation in the past attracted considerable attention but was not in general seen as evidence in support of either the expanding Earth or the $G(t)$ hypothesis (e.g. Holmes, 1965, pp. 972-975; Wells, 1966; Runcorn, 1967, p. 11). 


\section{Does expansion depend on $G(t)$ ?}

The dissociation of continental drift in the sense of Wegener and continental spreading can be found in several advocates of the expanding Earth. The topology of Earth, wrote the Australian geologist Fairbridge (1966, p. 143), "is not the product of continents floating apart on a globe of fixed radius, but the growth of a new oceanic crust, the continents remaining more or less in their same altitudes vis-à-vis each other, but merely further apart or somewhat rotated." Fairbridge suggested that there had been an early and rapid Mesozoic expansion some 200 million years ago. The expansion still continued today, but at a slower rate comparable to the one argued by Egyed. While favouring the expansion of Earth, contrary to Egyed and Jordan, Fairbridge did not support the $G(t)$ hypothesis, which he thought was inconsistent with palaeoclimatological evidence: "The evidence of palaeoclimatology favours the concept of expansion, but is opposed to change of the gravitational constant." All the same, Fairbridge did not simply dismiss the hypothesis: "According to Einstein, the Universe is expanding, and Dirac (1938) concluded that gravitation must decrease with time. ... A test of such a theory would be the demonstration of a slow expansion of our globe." (Fairbridge, 1964, pp. 60 and 83).

Many of the earth scientists in favour of the expanding Earth simply ignored the $G(t)$ explanation or just mentioned it briefly. Among those who considered the hypothesis, some ruled it out as unnecessary and extravagant or dismissed it for empirical reasons, such as Fairbridge did. Another example is provided by Elena Alexandrovna Lubimova, a geophysicist at the Academy of Sciences in Moscow, who argued that a modest expansion was a natural consequence of the thermal evolution of Earth. "There is no necessity to involve some speculative theory, connected with the variation of universal constant," she wrote (Lubimova, 1967, p. 310). According to the Russian geophysicist the expansion rate was originally, shortly after the formation of Earth, $7 \times 10^{-3} \mathrm{~cm} \mathrm{yr}^{-1}$ and had at present decreased to $3 \times 10^{-3} \mathrm{~cm} \mathrm{yr}^{-1}$; during the first billion years the radius of Earth had increased by only 50 $100 \mathrm{~km}$. The view of a decreasing rather than an increasing slow expansion was unusual and contrary to, for example, the ideas of the leading expansionist Samuel Warren Carey, professor of geology at the University of Tasmania. Yet Lubimova's reasoning and result received support from another expansionist, the Italian geophysicist Ranalli (1971).

Carey may have been aware of the $G(t)$ hypothesis at the time of the 1956 Hobart symposium on continental drift where he first suggested that "The diameter of the [ancient] Earth was less than half its present diameter and its surface area less than a quarter of its present surface" (Carey, 1958, p. 346). However, conceiving the rapid expansion as an empirical conclusion he did not mention the Dirac-Jordan hypothesis or any other physical cause. Carey realised that the expansion might be inexplicable in terms of known physics but this he considered to be a problem for the physicists

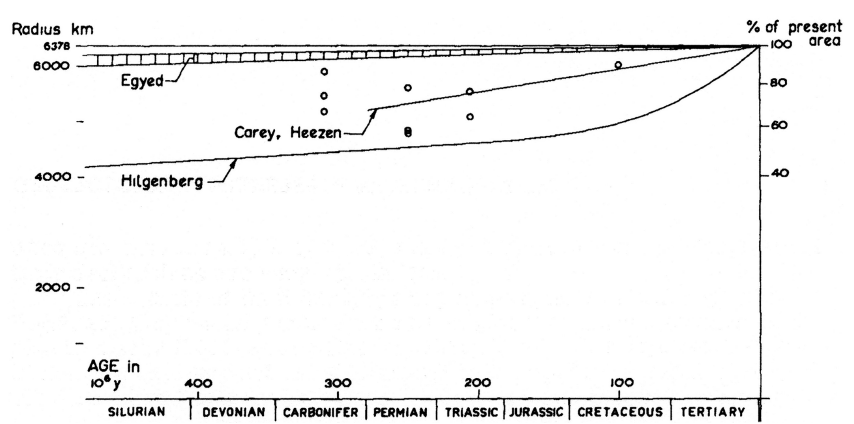

Figure 3. Slow (Egyed) and fast (Carey, Heezen) versions of Earth expansion according to van Hilten. The small circles refer to palaeomagnetic data. The curve labelled "Hilgenberg" refers to the German engineer Ott C. Hilgenberg, who in 1933 published Vom wachsenden Erdball and in the 1960s joined the new expansionism. Source: Van Hilten (1964).

rather than the geologists. Although he considered the $G(t)$ hypothesis in some of his later publications, he never embraced it (Carey, 1976, pp. 446-453).

The Dutch geophysicist D. van Hilten was one of the few earth scientists who agreed with Carey's rapid expansion (Fig. 3). According to Van Hilten $(1963,1964)$ Earth's radius in the Carboniferous was only $80 \%$ of its present radius. Much like Carey, he declined speculating about the cause of the expansion and he did not refer to the $G(t)$ hypothesis.

Contrary to Carey and van Hilten, the British geophysicist Creer $(1965 \mathrm{a}, \mathrm{b})$ believed that most of the expansion took place during the Archeozoic (or Archeon) whereas it played a very minor role in the Mesozoic era. Creer suggested that expansion had occurred over a period of 3.5 billion years, starting at the time when Earth had a radius of only $0.55 R_{0}$, where $R_{0}=6378 \mathrm{~km}$ is the present value. By simulating the expansion process he estimated that in the early Palaeozoic, some 544 million years ago, Earth would have swelled to $0.95 R_{0}$ and to about $0.97 R_{0}$ by the end of the era. For the average rate of expansion he suggested the value $0.75 \mathrm{~mm}$ per year. Although Creer did not refer to the Dirac-JordanEgyed hypothesis of $G(t)$, he did suggest that the expansion of Earth might have a cosmological origin of some kind. "We should beware of rejecting the hypothesis of expansion out of hand on grounds that no known sources of energy are adequate," he wrote (Creer, 1965a, p. 539).

According to some geophysicists there were adequate sources of energy in Earth itself. Assuming Earth to be of uniform density and constant mass, its gravitational potential energy is

$E_{\text {grav }}=-\frac{3}{5} \frac{G M^{2}}{R}$.

Thus, an increase in Earth's palaeoradius $R$ requires an injection of energy. As the Canadian geophysicist Alan Beck pointed out, the situation is different for a non-uniform Earth, which can expand and lose gravitational energy at the same 
time. He argued that "expansions of the order of $100 \mathrm{~km}$ seem quite possible without postulating any source of energy" (Beck, 1960, 1969; see also Cook and Eardley, 1961). On the other hand, Beck found a radial increase of the order of $1000 \mathrm{~km}$ to be improbable even if the effects of radioactivity were taken into account. Such an expansion would need a non-conventional cause of some kind, perhaps in the form of varying gravity.

According to the London geologist Raymond Dearnley, various methods of estimating the growth of Earth "strongly suggest a relatively uniform rate of expansion of the Earth's radius of about $0.65 \pm 0.25 \mathrm{~mm}$ per year as far back as 4500 Mya” (Dearnley, 1966, p. 32, 1965). At the 1967 Newcastle meeting on geophysics he repeated the conclusion, noting that the value was almost the same as the cosmological Hubble expansion rate (Dearnley, 1969; MacDougal et al., 1963). Consider Hubble's recession law according to which the recession velocity $v$ of a galaxy at distance $r$ is given by

$v=H_{0} r$

The widely accepted value for the Hubble constant $H_{0}=100 \mathrm{~km} \mathrm{~s}^{-1} \mathrm{Mpc}^{-1}$ translates into $H_{0}=$ $1.03 \times 10^{-4} \mathrm{~mm} \mathrm{yr}^{-1} \mathrm{~km}^{-1}$ and if inserted in the Hubble relation with $r=R_{0}$ the result becomes $v=0.66 \mathrm{~mm} \mathrm{yr}^{-1}$ - remarkably close to the rate of increase of Earth's radius. To some geologists, this was more than just a coincidence (Carey, 1976, p. 456, 1988, p. 330). Without committing himself, Dearnley was favourably inclined to a $G(t)$ explanation based on the theories of Dirac, Gilbert and Dicke. However, like several other protagonists of the expanding Earth he pointed out that a decrease in $G$ alone would be insufficient to account for the fast expansion. A weaker $G$ in the past had to be supplemented by some other cause, most likely phase changes in Earth's mantle such as discussed by Egyed and Creer among others.

\section{Sympathisers: Wilson and Holmes}

Several earth scientists expressed a positive interest in Earth expansion based on the $G(t)$ hypothesis without committing themselves to either of the ideas. Bruce Heezen, one of the early supporters of the expanding Earth theory and later of plate tectonics, did not care much for the cause of the expansion. "I personally have no strong feelings concerning the specific mechanism of expansion," said Heezen in 1960. "I simply conclude from the morphological and palaeomagnetic results that expansion has occurred" (Frankel, 2012b, p. 417). All the same Heezen did consider the cause, which he thought might be a combination of $G(t)$ and Egyed's idea of density changes within the interior of Earth. "A decrease in the force of gravity combined with internal density changes would produce a very large expansion," he declared (Heezen, 1960, p. 110).
Another of the later contributors to the plate tectonics revolution, the Canadian John Tuzo Wilson at the University of Toronto, shifted to mobilism and continental drift in 1961. His shift was facilitated by a brief flirtation with the idea that Earth had expanded as a result of decreasing gravity. Citing Dirac, Teller, Dicke and Egyed (but not Jordan) he admitted that a slow expansion might be caused by other factors, such as phase changes in the interior of Earth. On the other hand, "a decrease in $G$ remains an inviting idea" (Wilson, 1960, p. 882). On the basis of recent estimates of the area covered by the mid-oceanic ridges, Wilson calculated that their formation would require an increase of Earth's circumference of about $6 \%$ in "all geological time," which corresponds to an annual increase in radius of approximately $0.8 \mathrm{~mm}$. Wilson expressed serious interest in the expanding Earth and $G(t)$, which he found could explain global tectonics as well or even better than the contracting Earth. He explicitly rejected expansion as an explanation for continental drift. However, his interest in the expanding Earth hypothesis turned out to be nothing but a brief flirt. Having convinced himself that the continents were moving apart in accordance with Wegener's old idea he did not return to speculations about gravity varying in time or to the expanding Earth.

The highly esteemed geologist Arthur Holmes found Egyed's ideas to be interesting and promising, including his use of Dirac's cosmological theory. In a letter dated $30 \mathrm{Au}-$ gust 1959 to the Hungarian geophysicist he referred to the steady-state theory of the universe which at the time was much discussed in Britain as a possible alternative to relativistic evolution theories (Frankel 2012a, p. 287):

If the "steady-state" hypothesis of the universe turned out to be correct (which heaven forbid!) surely $G$ would remain constant? However, ... it seems reasonably certain that $G$ is decreasing with time. It may even turn out that all the other evidence for an expanding Earth is also evidence that $G$ is decreasing and that the "steady-state" concept is wrong. But that is probably looking too far ahead. Meanwhile a varying $G$ provides much that we need, though I wonder if it would be enough, by itself.

In the revised 1965 edition of his influential textbook Principles of Physical Geography, Holmes dealt in some detail with the expanding Earth and its relation to the contemporaneous cosmological debate (Holmes, 1965, pp. 983-987). While not embracing the big-bang theory, he did not embrace the rival steady-state theory either. In line with what he had written to Egyed, he thought that the expanding Earth contradicted the latter cosmology which he much disliked:

Fortunately our own concern, as geologists, is with the Earth, and our geological interest in the steadystate hypothesis lies in its implication that $G$, the constant of gravitation, also remains steady and really is a constant. But, if so, the expansion of the 
Earth is left without an explanation. Conversely, and this is of particular importance to astronomers, the expansion of the Earth is a powerful argument against the steady state.

The classical steady-state cosmological theory was indeed incompatible with a varying $G$, but so were the cosmological models based on the equations of general relativity, whether of the big-bang kind or some other kind. Holmes thought mistakenly that $G(t)$ could be used to discriminate between steady-state cosmology and cosmological models based on Einstein's field equations. Much like Egyed, Holmes uncritically accepted Gilbert's claim that Dirac's $G(t)$ hypothesis was consistent with the standard theory of general relativity.

Holmes was at the time sympathetic to the expanding Earth, if by no means committed to the hypothesis. His preferred value for the increase in radius was $0.5 \mathrm{~mm}$ per year or $100 \mathrm{~km}$ in the course of the past 200 million years, about the same value that Egyed and Dicke proposed. On the other hand, Carey's value for the same period was approximately $8 \mathrm{~mm}$ per year. According to Holmes, the major role of the expansion was not to move the continents, but to provide energy for the mantle convection which, in his view, was complementary to global expansion. He suggested that there was no reason to choose between continental drift and the expanding Earth: "Convection does not exclude global expansion. Global expansion does not exclude convection. And the combination is stronger than either separately" (Holmes, 1965 , p. 967). At the end of his book, Holmes referred to the possibility of a cosmological cause for the expansion brought about by a relief of pressure: "There seems to be only one possibility in the light of present knowledge: that the terrestrial force of gravity, which can be represented by $g\left[=G M / R^{2}\right]$, has systematically decreased as the Earth has grown older. ... The universal constant of gravitation, $G$, may have decreased with time, as inferred by P. A. M. Dirac in 1938."

\section{Degeneration}

By the late 1960s only a small minority of earth scientists considered the expanding Earth a viable alternative to continental drift. Most geophysicists saw palaeomagnetic measurements as a strong argument against Earth expansion, a hypothesis they had no need for and which appeared increasingly irrelevant in the light of progress in plate tectonics. As interest in the expanding Earth waned, so did the interest in explaining the expansion in terms of varying gravity. Nevertheless, the two connected yet independent hypotheses continued to be subjects of investigation, both theoretically and empirically. The varying- $G$ theories discussed in the 1960s were those of Dirac, Jordan and Dicke, and in the early 1970s a new cosmological theory of this kind was proposed by Hoyle and Narlikar $(1971,1972)$.
One version of the Hoyle-Narlikar theory operated with a gravitational constant decreasing in time in a manner similar to Dirac's original theory. Of interest in the present context, the two Cambridge cosmologists not only discussed the astrophysical consequences of their theory but also the consequences for the structure of Earth. "In principle geophysics could be of decisive importance to cosmology," they pointed out (Hoyle and Narlikar, 1972, p. 332). Hoyle and Narlikar suggested that the expansion of Earth, a result of the decreasing force of gravity, provided the force that makes the continents drift apart. With $q$ denoting a number for unity, they obtained for the rate of increase of Earth's radius:

$\frac{\mathrm{d} R}{\mathrm{~d} t} \cong 10 q \mathrm{~km}$ per $10^{8} \mathrm{yr}=0.1 q \mathrm{~mm} \mathrm{yr}^{-1}$

That is, the expansion rate would be of the same order as the one proposed by Egyed and Dicke.

On 11 February 1972 Hoyle, serving as President of the Royal Astronomical Society, gave an address on "The History of the Earth" that dealt as much with geophysics as with planetary astronomy. As Jon Darius, a London astronomer, commented in a report on Hoyle's lecture, "Various eyebrows mounted as Hoyle elaborated on the planetary, stellar, and geophysical effects of a time-varying $G$ " (Darius, 1972). Claiming that there was "a considerable body of evidence" supporting a decreasing $G$, Hoyle considered the effects on the motion of the Moon, solar luminosity, the temperature of Earth in the past, and the motion of the continents. All of these subjects had been covered in detail previously, but now Hoyle reconsidered them from the point of view of the Hoyle-Narlikar gravitation theory (Hoyle, 1972). For the rate of increase of Earth's radius he calculated a value between 6 and $10 \mathrm{~km}$ per $10^{8}$ years $\left(\sim 0.1 \mathrm{~mm} \mathrm{yr}^{-1}\right)$, suggesting that the expansion combined with mantle convection explained how the continental plates were set in horizontal motion.

Hoyle's somewhat amateurish excursion into geophysics made even less of an impact than Jordan's longer and more serious excursion. Hugh Owen, a palaeontologist and cartographer at the British Museum, was among the few who found Hoyle's theory promising. A late advocate of the expanding Earth, he suggested that Earth's diameter was approximately half its current value 700 million years ago (Owen, 1976, 1984; Fig. 4). Hoyle's old friend and collaborator, the Cambridge astronomer Raymond Lyttleton, did not believe in continental drift. In a critical reply to the Hoyle-Narlikar hypothesis, he and his collaborator John Finch recalculated the change of Earth's radius on the assumption of $G \sim 1 / t$ and Ramsay's hypothesis of the inner Earth. They found a rate of change in radius of $\mathrm{d} R / \mathrm{d} t \cong 2.3 \mathrm{~km}$ per $10^{8} \mathrm{yr}$, or less than a quarter of the value reported by Hoyle and Narlikar. "It is clearly impossible," they concluded, "that a decreasing $G$ could alone cause expansion on such a scale that a fissure between Africa and South America would yawn some $5000 \mathrm{~km}$ in width" (Lyttleton and Finch, 1977). 


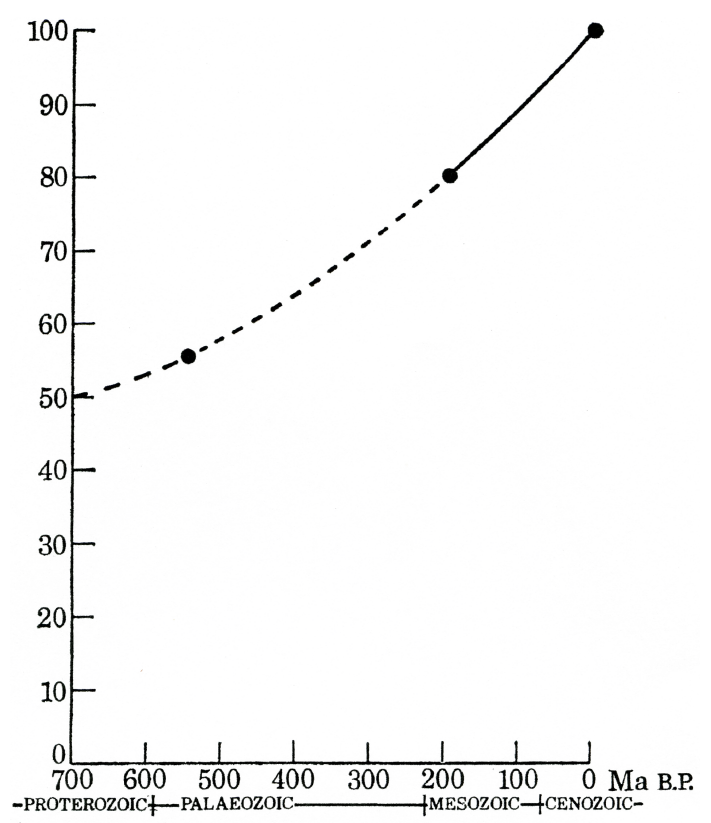

Figure 4. The expanding Earth, fast expansion rate. Values of Earth's radius through time, assuming a complete sialic crust at a radius of about $55 \%$ of the modern radius. Source: Owen (1976, p. 230).

At the latest, by 1980 the expanding Earth theory had been marginalised, separated off from mainstream geophysics and eventually to evolve into a theory with features of pseudoscience (Sudiro, 2014). However, attempts to test the $G(t)$ hypothesis, whether associated with the earth sciences or not, continued. Most of these attempts were of an astronomical nature, but a few were based on geophysical and archaeological reasoning (Pannella, 1972; Blake, 1977).

Alexander Stewart, a geologist at the University of Reading, focused on the gravitational acceleration $g$ at the surface of Earth rather than on the universal constant $G$. Since $g=G M / R^{2}$, if Earth expands as the result of a weakening $G$, the variation in $g$ will be stronger than the $G$ variation (Fig. 5). From a variety of palaeontological evidence, ranging from the permanent existence of an atmosphere since the Archaean to the mineralogical composition of ancient clays, Stewart suggested that in the Archaean, some 3.7 billion years ago, $g \leq 1.2 g_{0}$. Assuming $M=$ constant the limit corresponded to

$\frac{1}{G} \frac{\mathrm{d} G}{\mathrm{~d} t} \leq 2.4 \times 10^{-10} \mathrm{yr}^{-1}$

This was a fairly sharp constraint, but not quite sharp enough to test the cosmological models assuming $G(t)$. Stewart generally concluded that his data "flatly contradict rapid Earth expansion models" such as those preferred by Carey, Owen and van Hilten (Stewart, 1978, p. 155, 1983).

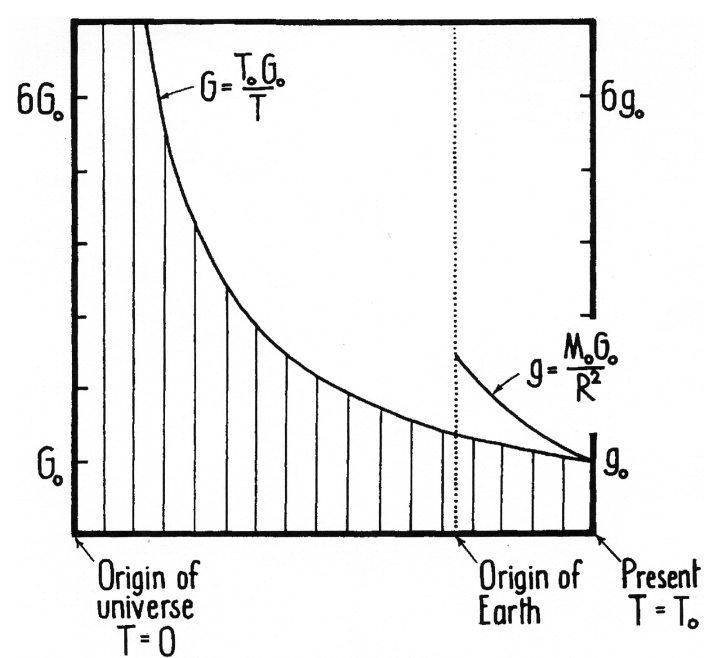

Figure 5. The cosmic decrease of $G$ according to Dirac compared to the decrease of Earth's surface gravity $g$. Source: Stewart (1977, p. 281).

Models of this type can be represented by the expression

$R(T) \cong R_{0}[0.6+0.4 \exp (-k T)]$.

$R_{0}$ is the present radius of Earth, $T$ is the time in the past ( $T=0$ at present) and $k$ is a constant of the order of $5 \times 10^{-9} \mathrm{yr}^{-1}$. The average expansion rate is $\sim 1 \mathrm{~cm} \mathrm{yr}^{-1}$. The primeval Earth is assumed to have had a radius of 0.6 $R_{0}=3820 \mathrm{~km}$. While Stewart was confident that models of this kind could be ruled out, he admitted that models of slow expansion, such as Egyed's and Dicke's, survived his test.

The relationship between $R(t)$ and $G(t)$ can in general be written as

$\frac{1}{R} \frac{\mathrm{d} R}{\mathrm{~d} t}=-\frac{\alpha}{G} \frac{\mathrm{d} G}{\mathrm{~d} t}$,

where $\alpha$ is a quantity depending on the equation of state of Earth. By calculating $\alpha$ in terms of pressure and density an estimate for the rate of $G(t)$ can be obtained. Based on palaeomagnetic data, McElhinny et al. (1978) found $\alpha=$ $0.085 \pm 0.02$, from which they concluded that the radius of our globe cannot have expanded more than $0.8 \%$ over the past 400 million years. For the rate of change of $G$ they derived an upper limit of $8 \times 10^{-12} \mathrm{yr}^{-1}$, a value in conflict with Dirac's $G \sim 1 / t$ and also with the Hoyle-Narlikar theory. According to Peter Smith, a geophysicist at the Open University, the day that McElhinny and his collaborators published their paper was "a bad day for the handful of people who support the idea of an expanding Earth" (Smith, 1978).

\section{Conclusions}

From the perspective of modern geophysics the hypothesis of an expanding Earth may appear to have been just a somewhat 
irrelevant parenthesis in the development, which in the late 1960s led to the paradigmatic theory of plate tectonics. A parenthesis it was, but for a time it played a relatively important role, which is reason enough that it deserves more than just a footnote in the historical annals of modern geophysics. The subclass of expansion theories that relied on the $G(t)$ hypothesis is of particular interest because it provided a surprising link between, on the one hand, modern cosmological theory and, on the other, the geological and palaeontological sciences.

Despite attempts to defend the expanding Earth, the hypothesis has for long ceased to attract interest among mainstream geophysicists (Sudiro, 2014). Using advanced geodetic methods and measurement techniques a recent study has confirmed that Earth does not expand. Although the scientists conducting the study (Wu et al., 2011) found a tiny expansion rate of about $0.1 \mathrm{~mm}$ per year, with a measurement uncertainty of $0.2 \mathrm{~mm}$ per year, the expansion was not statistically significant. The $G(t)$ hypothesis has fared no better, as analysis of data from the Lunar Laser Ranging Project (Müller and Biskupek, 2007) has today resulted in a variation of

$$
\frac{1}{G} \frac{\mathrm{d} G}{\mathrm{~d} t}=(2 \pm 7) \times 10^{-13} \mathrm{yr}^{-1}
$$

All the same, Dirac's old idea that some of the fundamental constants of nature may vary in time continues to fascinate physicists and cosmologists (Uzan, 2003).

Edited by: G. A. Good

Reviewed by: M. Greene and one anonymous referee

\section{References}

Beck, A. E.: An expanding Earth with loss of gravitational potential energy, Nature, 185, 677-678, 1960.

Beck, A. E.: Energy changes in an expanding Earth, in: The Application of Modern Physics to the Earth and Planetary Interiors, edited by: Stanley, K., Runcorn, London, Wiley Interscience, 7786, 1969.

Blake, G. M.: The rate of change of $G$, Month. Not. Roy. Astron. Soc., 178, 41P-43P, 1977.

Brush, S. G.: A History of Modern Planetary Science, Vol. 1: Nebulous Earth, Cambridge, Cambridge University Press, 1966.

Carey, S. W.: A tectonic approach to continental drift, in: Continental Drift: A Symposium, edited by: Carey, S. W., Hobart, Tasmania, University of Tasmania, 177-355, 1958.

Carey, S. W.: The Expanding Earth, Amsterdam, Elsevier, 1976.

Carey, S. W.: Theories of the Earth and Universe: A History of Dogma in the Earth Sciences, Stanford, CA, Stanford University Press, 1988.

Cook, M. A. and Eardley, A. J.: Energy requirement in terrestrial expansion, J. Geophys. Res., 66, 3907-3912, 1961.

Creer, K. M.: An expanding Earth?, Nature, 205, 539-544, 1965a.

Creer, K. M.: Tracking the Earth's continents, Discovery (Popular Journal of Knowledge), 26, 34-40, 1965b.

Darius, J.: Rethinking the universe, New Scientist, 53, 482-483, 1972.
Dearnley, R.: Orogenic fold-belts, convection and expansion of the Earth, Nature, 206, 1284-1290, 1965.

Dearnley, R.: Orogenic fold-belts and a hypothesis of Earth evolution, Phys. Chem. Earth, 7, 1-114, 1966.

Dearnley, R.: Crustal tectonic evidence for Earth expansion, in: The Application of Modern Physics to the Earth and Planetary Interiors, edited by: Runcorn, S. K., London, Wiley Interscience, 103-110, 1969.

Dirac, P. A. M.: The cosmological constants, Nature, 139, p. 323, 1937.

Dirac, P. A. M.: A new basis for cosmology, Proc. Roy. Soc. A, 165, 199-208, 1938.

Egyed, L.: Determination of changes in the dimension of the Earth from palæogeographical data, Nature, 173, p. 534, 1956a.

Egyed, L.: The change of the Earth's dimensions determined from paleogeographical data, Geofis. Pur. Applic., 33, 42-48, 1956b.

Egyed, L.: A new dynamic conception of the internal constitution of the Earth, Geol. Rundschau, 46, 101-121, 1957.

Egyed, L.: On the origin and constitution of the upper part of the Earth's mantle, Geol. Rundschau, 50, 251-258, 1960a.

Egyed, L.: Some remarks on continental drift, Geofis. Pur. Applic., 45, 115-116, 1960b.

Egyed, L.: Vom Aufbau der Erde, in: Die Erde, edited by: TasnádiKubacska, A., Leipzig, Urania-Verlag, 48-103, 1965.

Egyed, L.: The slow expansion hypothesis, in: The Application of Modern Physics to the Earth and Planetary Interiors, edited by: Runcorn, S. K., London, Wiley Interscience, 65-75, 1969a.

Egyed, L.: Physik der Festen Erde, Leipzig, Teubner, 1969b.

Egyed, L. and Stegena, L.: Physical background of a dynamical Earth model, Zeitschrift für Geophysik, 24, 260-267, 1958.

Fairbridge, R. W.: Thoughts about an expanding globe, in: Advancing Frontiers in Geology and Geophysics, edited by: Subramanian, A. P. and Balakrishna, S., Hyderabad, Indian Geophysical Union, 59-88, 1964.

Fairbridge, R. W.: Endospheres and interzonal coupling, Ann. New York Acad. Sci., 140, 133-148, 1966.

Frankel, H. R.: The Continental Drift Controversy, Vol. 2: Paleomagnetism and Confirmation of Drift, Cambridge, Cambridge University Press, 2012a.

Frankel, H. R.: The Continental Drift Controversy, Vol. 3: Introduction of Seafloor Spreading, Cambridge, Cambridge University Press, $2012 b$.

Gilbert, C.: Dirac's cosmology and the general theory of relativity, Month. Not. Roy. Astron. Soc., 116, 684-690, 1956.

Heezen, B. C.: The rift in the ocean floor, Sci. Am., 203, 98-110, 1960.

Holmes, A.: Principles of Physical Geology, New York, Ronald Press, 1965.

Hoyle, F.: The history of the Earth, Q. J. Roy. Astron. Soc., 13, 328-345, 1972.

Hoyle, F. and Narlikar, J. V.: On the nature of mass, Nature, 233, 41-44, 1971.

Hoyle, F. and Narlikar, J. V.: Cosmological models in a conformally invariant gravitational theory, II, Month. Not. Roy. Astron. Soc., 155, 323-335, 1972.

Joksch, H. C.: Statitische Analyse der hypsometrischen Kurve der Erde, Zeitschrift für Geophysik, 21, 109-112, 1955.

Jordan, P.: Schwerkraft und Weltall: Grundlagen der theoretischen Kosmologie, Braunschweig, Vieweg \& Sohn, 1952. 
Jordan, P.: Schwerkraft und Weltall: Grundlagen der theoretischen Kosmologie, 2nd Edn., Braunschweig, Vieweg \& Sohn, 1955.

Jordan, P.: Geophysical consequences of Dirac's hypothesis, Rev. Mod. Phys., 34, 596-600, 1962a.

Jordan, P.: Empirical confirmation of Dirac's hypothesis of diminishing gravitation, in: Recent Developments in General Relativity, Oxford, Pergamon Press, 283-288, 1962b.

Jordan, P.: On the possibility of avoiding Ramsey's hypothesis in formulating a theory of Earth expansion, in: The Application of Modern Physics to the Earth and Planetary Interiors, edited by: Runcorn, S. K., London, Wiley Interscience, 55-62, 1969.

Kragh, H.: Dirac: A Scientific Biography, Cambridge, Cambridge University Press, 1990.

Kragh, H.: Cosmonumerology and empiricism: The Dirac-Gamow dialogue, Astron. Quart., 8, 109-126, 1991.

Kragh, H.: Gravitation and the earth sciences: The contributions of Robert Dicke, Arxiv: 1501.04293 [physics.hist-ph], 2015.

Le Grand, H. E.: Drifting Continents and Shifting Theories, Cambridge, Cambridge University Press, 1988.

Lubimova, E. A.: Theory of thermal state of the Earth's mantle, in: The Earth's Mantle, edited by: Gaskell, T. F., London, Academic Press, 231-326, 1967.

Lyttleton, R. A. and Fitch, J. P.: Cosmological change of $G$ and the structure of the Earth, Month. Not. Roy. Astron. Soc., 180, 471477, 1977.

MacDougall, J., Butler, R., Kronberg, G., and Sandqvist, A.: A comparison of terrestrial and universal expansion, Nature, 199, p. $1080,1963$.

McElhinny, M. W., Taylor, S. R., and Stevenson, D. J.: Limits to the expansion of Earth, Moon, Mars and Mercury and to changes in the gravitational constant, Nature, 271, 316-321, 1978.

Menard, H. W.: The Ocean of Truth: A Personal History of Global Tectonics, Princeton, Princeton University Press, 1986.

Müller, J. and Biskukep, L.: Variations of the gravitational constant from lunar laser ranging data, Classical Quant. Grav., 24, 45334538, 2007.

Nunan, R.: The theory of an expanding Earth and the acceptability of guiding assumptions, in: Scrutinizing Science: Empirical Studies of Scientific Change, edited by: Donovan, A., Laudan, L., and Laudan, R., Dordrecht, Kluwer Academic, 289-313, 1988.

Nunan, R.: Expanding Earth theories, in: Sciences of the Earth: An Encyclopedia of Events, People, and Phenomena, Vol. 2, edited by: Good, G. A., New York, Garland Publishing, 243-250, 1998.

Oldroyd, D.: Thinking about the Earth: A History of Ideas in Geology, London, Athlone, 1996.

Oreskes, N. (Ed.): Plate Tectonis: An Insider's History of the Modern Theory of the Earth, Cambridge, Mass., Westview Press, 2001.

Owen, H. G.: Continental displacement and expansion of the Earth during the Mesozoic and Cenozoic, Phil. Trans. Roy. Soc. A, 281, 223-291, 1976.

Owen, H. G.: The Earth is expanding and we don't know why, New Scientist, 431, 27-29, 1984.

Pannella, G.: Paleontological evidence on the Earth's rotational history since early Precambrian, Astrophys. Space Sci., 16, 212 237, 1972.
Pauli, W.: Wissenschaftlicher Briefwechsel mit Bohr, Einstein, Heisenberg u.a., Vol. 4, Part 1, edited by: von Meyenn, K., Berlin, Springer, 1996.

Peebles, P. J. E. and Dicke, R. D.: The temperature of meteorites and Dirac's cosmology and Mach's principle, J. Geophys. Res., 67, 4063-4070, 1962.

Ramsay, W. H.: On the nature of the Earth's core, Geophys. J. Internat., 5 (suppl. 9), 409-426, 1949.

Ranalli, G.: The expansion-undation hypothesis for geotectonic evolution, Tectonophysics, 11, 261-285, 1971.

Runcorn, S. K.: Corals and the history of the Earth's rotation, Sea Frontiers, 13, 4-12, 1967.

Smith, P. J.: The end of the expanding Earth hypothesis? Nature, 271, p. 301, 1978.

Stewart, A. D.: Palaeogravity, in: Palaeogeophysics, edited by: Runcorn, S. K., London, Academic Press, 413-434, 1970.

Stewart, A. D.: Quantitative limits to palaeogravity, J. Geol. Soc. London, 133, 281-291, 1977.

Stewart, A. D.: Limits to palaeogravity since the late Precambrium, Nature, 271, 153-155, 1978.

Stewart, A. D.: Quantitative limits to the palaeoradius of the Earth, in: The Expanding Earth, a Symposium, edited by: Carey, S. W., Hobart, Tasmania, University of Tasmania, 305-319, 1983.

Sudiro, P.: The Earth expansion theory and its transition from scientific hypothesis to pseudoscientific belief, Hist. Geo Space. Sci., 5, 135-148, doi:10.5194/hgss-5-135-2014, 2014.

Teller, E.: On the change of physical constants, Phys. Rev., 73, 801802, 1948.

Termier, H. and Termier, G.: Global paleogeography and Earth expansion, in: The Application of Modern Physics to the Earth and Planetary Interiors, edited by: Runcorn, S. K., London, Wiley Interscience, 87-101, 1969.

Uzan, J.-P.: The fundamental constants and their variation: Observational status and theoretical motivations, Rev. Mod. Phys., 75, 403-459, 2003.

Van Hilten, D.: Palæomagnetic indications of an increase in the Earth's radius, Nature, 200, 1277-1279, 1963.

Van Hilten, D.: Evaluation of some geotectonic hypotheses by paleomagnetism, Tectonophysics, 1, 3-71, 1964.

Wegener, A.: The Origin of Continents and Oceans, New York, Dover Publications, 1966.

Wells, J. W.: Coral growth and geochronometry, Nature, 197, 948950, 1963.

Wells, J. W.: Paleontological evidence of the rate of the Earth's rotation, in: The Earth-Moon System, edited by: Marsden, B. G and Cameron, A. G. W., New York, Plenum Press, 70-81, 1966.

Wilson, J. T.: Some consequences of expansion of the Earth, Nature, 185, 880-882, 1960.

Wu, X., Collilieux, X., Altamimi, Z., Vermeersen, B., Gross, R. S., and Fukumori, I.: Accuracy of the International Terrestrial Reference Frame origin and Earth expansion, Geophys. Res. Lett., 38, L13304, doi:10.1029/2011GL047450, 2011. 